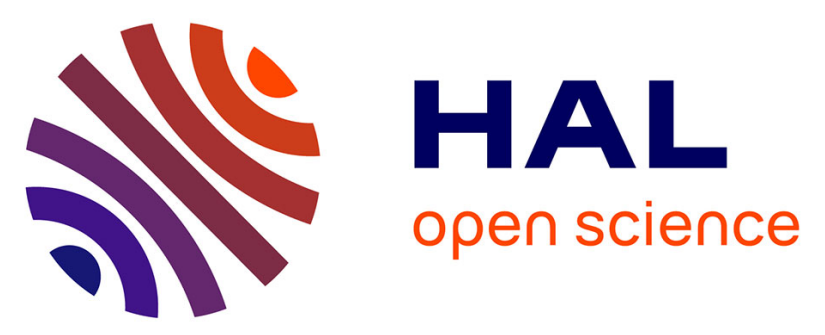

\title{
Nocturnal exploratory flights, departure time, and direction in a migratory songbird
}

Heiko Schmaljohann, Philipp J. J. Becker, Hakan Karaardic, Felix Liechti, Beat Naef-Daenzer, Celia Grande

\section{- To cite this version:}

Heiko Schmaljohann, Philipp J. J. Becker, Hakan Karaardic, Felix Liechti, Beat Naef-Daenzer, et al.. Nocturnal exploratory flights, departure time, and direction in a migratory songbird. Journal für Ornithologie = Journal of Ornithology, 2010, 152 (2), pp.439-452. 10.1007/s10336-010-0604-y . hal-00642375

\section{HAL Id: hal-00642375 \\ https://hal.science/hal-00642375}

Submitted on 18 Nov 2011

HAL is a multi-disciplinary open access archive for the deposit and dissemination of scientific research documents, whether they are published or not. The documents may come from teaching and research institutions in France or abroad, or from public or private research centers.
L'archive ouverte pluridisciplinaire HAL, est destinée au dépôt et à la diffusion de documents scientifiques de niveau recherche, publiés ou non, émanant des établissements d'enseignement et de recherche français ou étrangers, des laboratoires publics ou privés. 
1 Nocturnal exploratory flights, departure time and, direction in a migratory songbird

2

3 Heiko Schmaljohann, Philipp J. J. Becker, Hakan Karaardic, Felix Liechti, Beat Naef-Daenzer \& Celia

4 Grande

5

6 Correspondence and address: H. Schmaljohann, Institute of Avian Research, "Vogelwarte Helgoland",

7 An der Vogelwarte 21, 26386 Wilhelmshaven, Germany (email: heiko.schmaljohann@ifv-

$8 \quad$ vogelwarte.de).

9 phone: $0049-(0) 4421-96890$

10 fax: $0049-(0) 4421-968955$

11

12 H. Schmaljohann · P. J. J. Becker · H. Karaardic · C. Grande

13 Institute of Avian Research, "Vogelwarte Helgoland", An der Vogelwarte 21, 26386 Wilhelmshaven,

14 Germany

15 H. Karaardic

16 Akdeniz University, Art \& Science Faculty, Department of Biology, 07058 Antalya, Turkey

$17 \quad$ F. Liechti $\cdot$ B. Naef-Daenzer

18 Swiss Ornithological Institute, Luzernerstrasse 6, 6204 Sempach, Switzerland 
Stopover studies have concentrated so far mostly on mechanisms regulating the temporal organisation on the day-to-day level. Taking advantage of the small and isolated island of Helgoland in the North Sea, we investigated the stopover and departure behaviour of a nocturnal migrant by using radio telemetry. Special attention was paid particularly to nocturnal behaviour, their departure times within the night, and departure directions. Here we show that Northern Wheatears, Oenanthe oenanthe, performed regularly nocturnal exploratory flights on nights before and on departure night, which might be a common behaviour of nocturnal migrants to evaluate meteorological conditions aloft prior to departure. We proposed that migrants being prepared for an endurance flight would depart early in the night within a short time window, whereas individuals departing with low fuel load would be less prone to take off early. Our data, however, could not support this hypothesis. In respect of the migratory direction there was a significant correlation between departure direction and departure fuel load. Northern Wheatears with high departure fuel loads headed more towards north than lean migrants, which departed mostly towards the nearest coastline, i.e. east to south. Thus, birds with high fuel loads showed their seasonally appropriate migratory direction irrespectively of the ecological barrier ahead, whereas lean birds avoided this direction. To our knowledge, this is the first study that investigates the relationship of fuel load and departure direction in a free-flying songbird.

Keywords: Northern Wheatear $\cdot$ exploratory flight $\cdot$ departure time $\cdot$ departure direction $\cdot$ radio telemetry 
While migrating between breeding and wintering areas, birds spend far more of their time and energy at stopover sites than they do flying along their routes (Hedenström \& Alerstam 1997; Wikelski et al. 2003). Stopover ecology has taken over a major role in building up an understanding of how bird migration is organized. The optimal migration strategies from Alerstam \& Lindström (1990) predict how birds should organize their stopover in respect of time, energy, and predation (Houston 1998), which was confirmed by several studies (Hedenström 2007). It is now well understood, why migrants decide setting off from a stopover site during the season (Jenni \& Schaub 2003; Schaub et al. 2004; Tsvey et al. 2007; Schaub et al. 2008; Goymann et al. 2010) and what influences migrants' general flight directions (Liechti \& Bruderer 1998; Liechti 2006). Only little is, however, known about the nocturnal behaviour on the ground prior departure and why birds depart at a certain night-time and in a certain direction from a stopover site.

To investigate these issues, we conducted a radio telemetry study on an island in the German North Sea. Helgoland offers favourable conditions to investigate nocturnal behaviour of migrants, because (1) owing to its small size $\left(1 \mathrm{~km}^{2}\right)$ presence/absence can be precisely determined, (2) birds having left the island can be treated as having continued their migration, because next stopover sites are at least $50 \mathrm{~km}$ away, and (3) birds performing local nocturnal flights will not be misidentified as departing birds, because detection range of radio transmitters is larger than the study area itself. As the study species, we chose the Northern Wheatear, Oenanthe oenanthe, a trans-Sahara migrant, which assembles frequently in two subspecies on Helgoland during migration (Dierschke \& Delingat 2003). These birds of the nominate subspecies, O. o. oenanthe (oenanthe wheatears hereafter), breed in Scandinavia, whereas the subspecies $O$. o. leucorhoa (leucorhoa wheatears hereafter) breeds on Iceland, Greenland, and Eastern Canada. Individuals stopping over are, hence, from the same species but face different migratory goals during spring migration.

Migrants having decided not to set off at a certain night might seek for a sheltered site and rest to recover from sleep deprivation of the previous migratory flight (Schwilch et al. 2002). Thus, these birds are supposed to rest during the night, whereas birds preparing for departure might show a higher 
calibration (Cochran et al. 2004; Mouritsen et al. 2004), exploring weather conditions, and possibly performing short nocturnal flights to test meteorological conditions aloft (Liechti 2006). We hypothesize that nocturnally migrating songbirds show a higher night-time activity on departure night than on nights before.

Prior to departure, migrants need to calibrate their compasses for orientation. The appropriate cues are best available during the twilight period, hence nocturnally migrating songbirds are supposed to depart after this period (Moore 1987; Muheim et al. 2006a). This coincides well with the majority of departure events (Bruderer \& Liechti 1995; Liechti et al. 1997; Bruderer \& Liechti 1999;

Gauthreaux \& Belser 1999; Bolshakov et al. 2003; Bulyuk \& Tsevy 2006; Schmaljohann et al. 2007). However, such radar and mist-net data do not provide spatial and temporal information about departure events of a priori specifically selected individuals. Radio telemetry studies do so (Cooke et al. 2004) and revealed that individual departure events may occur much later in the night than the exodus of migrants after sunset might suggest (Cochran et al. 1967; Åkesson et al. 1996a; Moore \& Aborn 1996; Åkesson et al. 2001; Bolshakov \& Chernetsov 2004; Bolshakov et al. 2007), see also Bulyuk \& Tsvey (2006).

Factors influencing the day-to-day departure decision are also supposed to control for migrants' departure time within the night. These decisions are, generally, ruled by an interplay of environmental and endogenous factors (Jenni \& Schaub 2003) with meteorological conditions having a paramount effect on flight (Liechti 2006) and orientation performance (Åkesson et al. 2001), while other environmental factors such as predation danger (Fransson \& Weber 1997; Schmaljohann \& Dierschke 2005) and competition (Rappole \& Warner 1976; Dierschke et al. 2005) seem to play a less important role. Fuel deposition rate and stopover duration determine departure fuel load, which in turn defines the potential flight range. Combining the potential flight range with the direction provides the potential flight vector. Migrants with high fuel loads can reach their next migratory goal by a direct flight and can keep their seasonal appropriate migratory direction, whereas leaner birds may need to fly towards the nearest available stopover site. The latter may, hence, be forced to select a flight direction differing from the seasonal appropriate one, if stopover sites are not in the same direction as their overall migratory goal. The length of the potential flight vector might initiate the departure 
decision within the night: Intended long flights need to be initiated soon after sunset, whereas migrants with short flight vectors do not need to depart early to accomplish their flight during the dark. We hypothesize that migrant's nocturnal departure time is driven by its potential flight vector.

Migrant's potential flight vector plays also an important role for the departure direction, when birds face a particularly inhospitable range of their journey. Long potential flight vectors allow crossing any obstacle by a non-stop flight and keeping the seasonal appropriate migratory direction, whereas short flight vectors drive birds to a detour avoiding the barrier (Alerstam 2001; Sandberg 2003). Unfavourable weather conditions (Richardson 1982) and the inability to orientate sufficiently well (Komenda-Zehnder et al. 2002; Zehnder et al. 2002) might deviate birds' flight direction from the expected one as well. Departure direction can, therefore, only be explained in the light of bird's potential flight vector (Alerstam 1978; Lindström \& Alerstam 1986; Sandberg 1994; Åkesson et al. 1996b; Moore \& Aborn 1996; Sandberg \& Moore 1996; Sandberg 2003 ; Deutschlander \& Muheim 2009). We hypothesize that migrants with long potential flight vectors will adjust their departure direction more towards their migratory goal than migrants with short potential flight vectors. In respect of the subspecies, we hypothesize that oenanthe wheatears with long potential flight vectors depart towards north to northeast and leucorhoa birds towards northwest (Dierschke \& Delingat 2003), whereas lean birds of either subspecies might depart in any direction directly towards the mainland.

\section{Methods}

Study site

The study was conducted on the German island of Helgoland in the North Sea $\left(54^{\circ} 11^{\prime} \mathrm{N}\right.$, $\left.07^{\circ} 55^{\prime} \mathrm{E}\right)$; the distance to the nearest coast is about $50 \mathrm{~km}$. Helgoland consists of two islands: the main island ( $1 \mathrm{~km}^{2}$, Helgoland hereafter), on which the field study was carried out, and the small Düne island $\left(0.7 \mathrm{~km}^{2}\right.$, Düne hereafter), which lies $800 \mathrm{~m}$ to the east of Helgoland. The term "island" refers to both. 
During spring season 2008138 Northern Wheatears were trapped with spring traps baited with mealworms, Tenebrio molitor, throughout the daylight period from 6th April to 23rd May 2008.

Within 5 min until release, Northern Wheatears were aged and sexed by plumage colouration according to Svensson (1992), measured (maximum wing length to the nearest $0.5 \mathrm{~mm}$ after Svensson (1992)) and weighed to the nearest $0.2 \mathrm{~g}$ with a Pesola balance. Fat score was estimated on a nine-

130 class (Kaiser 1993) and size of the breast muscle on a four-class scale (Bairlein 1994). Each bird was

131 marked with an individual combination of one aluminium and four split colour-rings. Wing length was

132 used to identify the subspecies: males and females with wing lengths exceeding $102 \mathrm{~mm}$ and $97 \mathrm{~mm}$,

133 respectively, were treated as belonging to the Iceland/Greenland subspecies $O$. o. leucorhoa, whereas

134 wing lengths below $99 \mathrm{~mm}$ (males) and $96 \mathrm{~mm}$ (females) indicated nominate birds (Svensson 1992).

135 Birds with wing length from the range of overlap were not assigned to a subspecies.

\section{Departure fuel load}

We compared fuel loads rather than body masses owing to the large size differences [range of wing length in this study: $92.5-110.5 \mathrm{~mm}$ ]. Lean body mass resulted from a linear regression of body mass from 220 Northern Wheatears with fat score $<2$ (only traces of fat visible) and muscle score $<2$ (low in breast muscle) caught on Helgoland in the years 1998-2002 and 2008: individual as: 
mass development of individually ringed Northern Wheatears could be surveyed; for further

153 information about this technique see Schmaljohann and Dierschke (2005). Birds' body mass from the

154 evening of departure (later than $7 \mathrm{pm}$ ) was defined as departure body mass. This procedure was

155 successful for four birds. Departure body masses of the others were modelled. Based on field data

156 from our northern wheatear research group on Helgoland, we estimated the $24 \mathrm{~h}$ ' (day + night) body

157 mass increase to be $0.9 \mathrm{~g}$ (Delingat et al. 2006, 2009).

158

159

\section{Flight range calculation}

160

The potential flight range of a bird depends on its departure fuel load, which corresponds to the available energy reserves. According to Delingat et al. (2008), flight range Y [km] can be estimated as:

163

$164 \mathrm{Y}_{\mathrm{i}}=100 \mathrm{U} \ln \left(1+\right.$ departure fuel $\left.\operatorname{load}_{\mathrm{i}}\right)$,

165

with $U$ as the average airspeed of a northern wheatear, which is $46 \mathrm{~km} / \mathrm{h}(13 \mathrm{~m} / \mathrm{s})$ after Bruderer \& Boldt (2001).

Direct flights to the breeding grounds lead leucorhoa wheatears towards northwest for 1700 $\mathrm{km}$ to Iceland or $2400 \mathrm{~km}$ to Greenland. No resting and refuelling sites are available en route for at least $700 \mathrm{~km}$ (Scotland). We divided leucorhoa wheatears into two groups: 1) with an estimated flight range exceeding $800 \mathrm{~km}$ (corresponding to departure fuel loads $\geq 0.19$ ) and 2) with shorter flight ranges. Leucorhoa wheatears of the latter group had insufficient fuel to cross the North Sea without any wind assistance. The breeding areas of oenanthe wheatears are to the north and east and hence, the next potential stopover sites are reachable with rather low fuel loads (Dierschke \& Delingat 2003; Delingat et al. 2008).

Radio transmitters 
181 elastic cord (Rappole \& Tipton 1990); length of leg-loops were adjusted individually to birds

182 according to Naef-Daenzer (2007). The elastic cord degraded when exposed to air, and radio

183 transmitters fell eventually off. Although radio-tagging birds is an interference, no adverse effects

184 were found, when transmitters had been fitted properly (Naef-Daenzer et al. 2001), and increase in

185 flight costs seemed to be low (Irvine et al. 2007). Radio transmitters, including battery and harness,

186 weighed $0.8 \mathrm{~g}$. Because lowest body mass of the Northern Wheatears was $21 \mathrm{~g}$ (mean $\pm \mathrm{SD}: 23.7 \pm 3$

$187 \mathrm{~g}$ ) in the present study, mass of radio transmitters represents at maximum 4\% (mean: $3.4 \%$ ) of birds

188 body mass. Thus, the relative load was lower than 5\%, which is suggested to be the upper permissible

189 load limit (Cochran 1980; Caccamise \& Hedin 1985).

Detection properties

Batteries' lifetime was about 30 days. Detection range was tested by placing a radio

transmitter on a ferry leaving the island and locating its position every few seconds by means of a GPS

194 device. We tracked the radio transmitter with Yagi 3EL2 antennas (Vårgårda, Sweden) in combination

195 with hand-held receivers, YAESU FT-290RII, from Helgoland. The detection range of the radio

196 transmitters depends on the orientation of transmitter's antenna, when pointing towards Helgoland

197 detection range was $8 \mathrm{~km}$, when turned by $45^{\circ} 10 \mathrm{~km}$ and when being perpendicular towards

198 Helgoland $15 \mathrm{~km}$, respectively. We tracked departing birds for (mean $\pm \mathrm{SD}) 15.3 \pm 8.5 \mathrm{~min}(n=26)$.

199 Because Northern Wheatear's airspeed is about $13 \mathrm{~m} / \mathrm{s}$ (Bruderer \& Boldt 2001), detection range was

200 approximately $12 \mathrm{~km}$, which coincided well with the predicted detection range from the ferry

201 experiment.

\section{Telemetry routine}

The 26 radio-tagged Northern Wheatears were tracked during all nights until their departure.

205 For convenient use each antenna was attached to a $2 \mathrm{~m}$ high wooden pole, where a compass was

206 aligned with the antenna axis. Location of the bird was from where the strongest signal came. To test

207 our accuracy of detection, we determined blindfolded the location of a fixed radio-transmitter in a 
distance of about $750 \mathrm{~m}$ (mean $\pm \mathrm{SD}$, deviation: $3 \pm 5^{\circ}, n=49$ ). We estimated our recordings of 209 departing Northern Wheatears to be correct to the nearest $3^{\circ}(n=4), 5^{\circ}(n=19)$, and $10^{\circ}(n=3)$ owing to our field experience. We searched the whole island shortly after each individual departure event and during the following day, but departed birds never recurred.

Nocturnal behaviour

We present here a first attempt to quantify bird's nocturnal behaviour on the ground. We assigned for each individual the different fluctuations in the received signal strength to different activity classes. This assignment was based on visual observations during daylight and the twilight period, when we could link fluctuations in the signal strength to defined activity classes. Unknown: Bird was located, but small fluctuations in the signal strength could not be recorded due to general tracking problems, strong wind or more than one bird to be tracked. Motionless: The signal strength was constant, hence, birds did not move.

Little activity: Fluctuations in signal strength were present but weak. We defined this category as small changes in bird's location, i.e. turning around or moving slightly for less than a metre.

High activity: Fluctuations in signal strength were strong, but birds did not fly. We defined such changes as high activity including movements for several meters. We observed that Northern Wheatears were searching for food during daytime and the twilight periods producing as strong fluctuations in the signal strength as we recorded during night-times. This suggests that Northern

227 Wheatears had fed during the night, which is supported by feeding until the onset of darkness

228 (Palmgren 1949; Ramenofsky et al. 2003) or even later (Morton 1967).

Exploratory flights: Northern Wheatears performed nocturnal flights for several minutes and landed afterwards at the same or a different site. To compare the nocturnal behaviour, we present here data of the first four activity classes as 232 relative proportions of the whole observation period per bird and corresponding night. Thus, the 233 different activity values sum up to $100 \%$ for the different groups (see Figs 1 and 2), but might be 234 based on differently long observation periods per bird and night depending on departure time and end 235 of observation. For some birds and nights no such data could be recorded. 
Weather data

We had two sources of meteorological data. From the Helgoland station of the German Weather Service we obtained cloud cover [x/8], cloud height [max $2500 \mathrm{~m}]$, wind speed $[\mathrm{m} / \mathrm{s}]$ and direction $\left[10^{\circ}\right]$, amount $[\mathrm{mm}]$, and duration $[\mathrm{min}]$ of precipitation at $2 \mathrm{~m}$ above sea level on an hourly basis. From the National Oceanic and Atmospheric Administration (NOAA, Boulder, Colorado, USA)

242 we downloaded NCEP Reanalysis wind speed and direction data

243 (http://www.cdc.noaa.gov/cdc/data.ncep.reanalysis.derived.html). We used data from four different 244 pressure levels $(1000,925,850$, and 700 mbar) representing four altitude intervals (ground level $445,445-1145,1145-2375$, and $2375-4000 \mathrm{~m}$, respectively). Because departure time was in all cases closest to the 0 a.m. data of NOAA, we considered only these data for our analyses. NOAA wind data correlated significantly with wind speed $(r=0.41, n=61, P=0.0001)$, and wind direction $\left(r_{C-C}=\right.$ 0.523, $n=61, P=0.0002$ (Jammalamadaka \& SenGupta 2001)) data from German Weather Service, so that we had confidence in considering NOAA data from higher altitudes for our analyses. different pressure levels per day around midnight. We defined the overall migratory goal for oenanthe wheatears as $80^{\circ}$ (mean departure direction in this study, see Fig. 1) and for leucorhoa wheatears as $315^{\circ}$ (direction towards Iceland and Greenland, see Fig. 2). Individual tailwind component was calculated as:

tailwind component $\mathrm{i}_{\mathrm{i}}=\cos \left(\right.$ wind direction $\mathrm{i}_{\mathrm{i}}-$ migratory goal $\left._{\mathrm{i}}\right) \mathrm{x}$ wind speed $_{\mathrm{i}}$.

\section{Predation danger}

We defined predation danger here according to Lank \& Ydenberg (2003), as the probability of becoming a prey if no antipredator behaviour was shown. Predation danger was assessed by daily

261 counts as the abundance of raptors posing a potential threat to Northern Wheatears: Eurasian

262 sparrowhawk, Accipiter nisus, common kestrel, Falco tinnunculus, merlin, F. columbarius, Eurasian hobby, $F$. subbuteo, and peregrine falcon $F$. peregrinus. 
Northern wheatear abundance

Daily counts of Northern Wheatears on Helgoland provided information about species' abundance indicating intraspecific competition.

Position of Sun

We used a freely available internet calculator for astronomical data

(http://www.sunearthtools.com/dp/tools/pos_sun.php ) to determine sun's elevation at the time of the exploratory flights and departures. Sun's elevation defines the different twilight periods: The Civil Twilight starts at sunset, when sun's elevation is at $0^{\circ}$ and ends when the top edge of the sun is $6^{\circ}$ below the horizon. The Nautical and Astronomical Twilight periods end at sun's elevation of $-12^{\circ}$ and $-18^{\circ}$, respectively (Fig. 3; Rozenberg 1966).

Statistics were calculated using the statistical software package R (R Development Core Team 2009) including packages "circular", "boot", and "bootstrap". Uniformity of directions was tested with the Rayleigh's Test of Uniformity (Batschelet 1981; Jammalamadaka \& SenGupta 2001). Circularcircular and circular-linear correlations were calculated following Jammalamadaka \& SenGupta 282 (2001). The p-value for a circular-linear correlation was approximated by bootstrapping. Out of each 283 circular and linear variable a certain number of values (here 26 equalling sample size of the radiotagged Northern Wheatears) were sampled randomly with replacement and their circular-linear correlation coefficient estimated. This was bootstrapped 2000 times in all cases. The number of such bootstraps with a correlation coefficient larger than the one of the original data set divided by the total number of bootstraps gives a robust estimate of the corresponding p-value (Crawley 2005). We analysed different variables possibly influencing sun's elevation at departure by Spearman's rank correlations. Although sun's position below the horizon is more crucial for departure decisions having a more important effect on orientation cues than simply the time elapsed after sunset,

291 we conducted the same analyses also with departure time after sunset as the response variable to 
compare our results with other studies. Duration from sunset to certain twilight periods changes in

293

294

295

296

297

298

299

300

301

302

303

304

305

306

307

308

309

310

311

312

313

314

315

316

317

318

319

course of the season, i.e., at a certain time after sunset sun's position varies with time of season (see Fig. 3).

Results

Here we present data from 26 radio-tagged Northern Wheatears, including 17 oenanthe (all 2nd year males) and 9 leucorhoa (five 2nd year, two adult males, and two 2nd year females) birds. Stopover duration after radio-tagging varied between 1 and 6 days (mean \pm SD: $1.9 \pm 1.3$ days, $n=$ 26); 15 birds stayed on Helgoland only for one day. Stopover duration did not differ between subspecies (Wilcoxon signed-ranks test: $T=76, n_{\text {oenanthe }}=17, n_{\text {leucorhoa }}=9, P=1$ ).

\section{Nocturnal behaviour}

Of the 26 radio-tagged birds, we could identify the nocturnal behaviour of 23 birds during departure night, of ten during the night before, of five during two nights before departure and of four on earlier nights, respectively. Nocturnal activity did not differ between the two nights before departure and departure night (see Fig. 4) and was generally rather low. Some birds showed only sometimes high activity on the ground. Although leucorhoa wheatears had a higher temporal proportion of little activity than oenanthe wheatears during departure night (Fig. 5), this difference was not statistically significant (ANOVA: $\mathrm{F}_{83,1}=0.0122, \mathrm{P}=0.912$ ) and oenanthe wheatears' behaviour was often categorized as unknown, which might disguise little activity.

\section{Exploratory flights}

During departure night ten out of 23 Northern Wheatears performed single exploratory flights, of which two birds showed twice such flight behaviour. The exploratory flights lasted between 1 and 9 min (mean \pm SD: $2.5 \pm 2.5$ min, $n=12$ ) and occurred from 48 to 314 min after sunset. Sun's elevation during the exploratory flights varied between $0.23^{\circ}$ and $-18.90^{\circ}$. In four cases birds landed in the same area, from where they had initiated their exploratory flights. They landed eight times at different sites 
on the island. Although we could estimate neither flight altitude nor range during the exploratory

321 flights, three birds covered at least $1 \mathrm{~km}$ during such flights, because they landed on the Düne before resuming migration. Actual departure after the first exploratory flight occurred when the sun was $8.7 \pm$ $4.6^{\circ}\left(\right.$ mean $\pm \mathrm{SD}$, range $\left.=0.6-14.3^{\circ}, n=10\right)$ further below the horizont or after $67 \pm 36 \min ($ mean \pm $\mathrm{SD}, n=10$, range $=15-120 \mathrm{~min}$; compare Fig. 6). The three Northern Wheatears that had rested on the Düne before departure set off from there after 60,79, and $110 \mathrm{~min}$, respectively. The time of the first exploratory flight until departure did not correlate significantly with sun's elevation at departure (Spearman rank correlation: $r_{S}=0.36, n=10, P=0.313$; Fig. 6). elevation was $-14.3 \pm-6.1^{\circ}$ (mean $\pm \mathrm{SD}$, range $\left.=-0.88--22.4^{\circ}, n=11\right)$ and time after sunset was 173 $\pm 71 \mathrm{~min}(\mathrm{mean} \pm \mathrm{SD}$, range $=55-168 \mathrm{~min}, n=11)$. During one night before departure four out of ten birds performed exploratory flights: One did three $\left(-14.4^{\circ},-17.2^{\circ},-18.1^{\circ}\right.$ and $159,213,258 \mathrm{~min}$ after sunset $)$, two birds two flights $\left(-0.9^{\circ},-15.5^{\circ}\right.$ and $55,187 \mathrm{~min} ;-20.1^{\circ},-22.4^{\circ}$ and $213,268 \mathrm{~min}$ after sunset, respectively) and one bird only one flight (-10.7 and $122 \mathrm{~min}$ after sunset). Only one out of five $\left(-17.3^{\circ}\right.$ and $225 \mathrm{~min}$ after sunset $)$ and one out of three $\left(-7.2^{\circ},-13.3^{\circ}\right.$ and $73,133 \mathrm{~min}$ after sunset) birds showed exploratory flights during two and three nights before departure, respectively. The ratios of birds performing and not performing exploratory flights per night did not differ significantly between the nights before departure and departure night (all 2-sample tests for equality of proportions: $\mathrm{P}>0.05)$. Although birds staying on the island could have perform their exploratory flights at lower sun's elevation than birds departing, sun's elevation of the first exploratory flights did not differ between these two (Wilcoxon signed-ranks test: $T=42, n_{\text {departure night }}=10, n_{\text {nights before departure }}=$ $3416, P=0.22)$. Northern Wheatears performing exploratory flights on the night before departure did not seem to have been prevented from setting off by unfavourable meteorological conditions, because they did not differ between their departure and previous night (tested for cloud cover, wind speed, wind 344 direction, and rain duration, all Wilcoxon signed-ranks tests: $P>0.15$ ). 
All Northern Wheatears departed well after the end of civil twilight, when the sun was at least $6^{\circ}$ below the horizon; mean sun's elevation \pm SD at departure was $-14.8 \pm 3.4^{\circ}(n=26$; median $=-$ $14.1^{\circ}$ ). Significantly more Northern Wheatears departed after the Nautical Twilight Period (sun's elevation $\left.-12^{\circ}\right)$ compared to the Nautical Twilight Period and before $\left(\chi^{2}=13, D f=1, n_{\text {after NTP }}=20\right.$, $n_{N T P \text { and before }}=6, P=0.0003$; Fig. 3). There was no significant difference between the two subspecies in sun's elevation (mean $\pm \mathrm{SD}$ ) at departure (oenanthe $-14 \pm 3.0^{\circ}$, median $=-13^{\circ}$; leucorhoa $-16 \pm$ $4.0^{\circ}$, median $=-16^{\circ}$, Wilcoxon signed-ranks test: $\left.T=102, n_{\text {oenanthe }}=17, n_{\text {leucorhoa }}=9, P=0.1815\right)$ and departure time after sunset (mean $\pm \mathrm{SD}$, oenanthe $172 \pm 56 \mathrm{~min}$, median = $163 \mathrm{~min}$; leucorhoa $203 \pm$ $81 \mathrm{~min}$, median $=208 \mathrm{~min}$, Wilcoxon signed-ranks test: $\left.T=57, n_{\text {oenanthe }}=17, n_{\text {leucorhoa }}=9, P=0.3057\right)$. Mean \pm SD departure time after sunset was $183 \pm 66 \min (n=26$, median $=176 \mathrm{~min})$.

\section{ii. influence of environmental factors on sun's elevation at departure}

Sun's elevation at departure of Northern Wheatears did neither correlate with wind direction $\left(r_{C-L}=0.15, n=26, F_{2,23} \approx 0.57, P>0.05\right)$ nor wind speed at ground level $\left(r_{S}=0.05, n=26, P=\right.$

0.793). There was also no significant correlation between sun's elevation and either tailwind component at the four pressure levels (all $r_{s}: P>0.15$ ). Cloud cover varied in general very little, but was slightly less at departure (mean $\pm \mathrm{SD}, 0.7 \pm 1.0$ ) than around sunset (mean $\pm \mathrm{SD}, 2.1 \pm 2.0$; Wilcoxon signed-ranked test: $T=177, n=26, P=0.002$ ). The statistical difference in cloud cover at 367 departure and around sunset has only little biological significance, because cloud cover at sunset was 368 in comparision to overcast situations very low. Cloud height did not have an influence on suns's 369 elevation at departure $\left(r_{S}=0.40, n=26, P=0.40\right)$. Precipitation was very low; it rained on three days 370 during the whole study period and only two birds departed during nights when light drizzle occurred. 371 We, consequently, omitted precipitation from our analysis. Time of season did not influence departure 372 time after sunset $\left(r_{S}=-0.1876, n=26, P=0.3587\right)$; here we could not test sun's elevation at departure 373 because of its apparent correlation with season. As in the abiotic factors, predation pressure $\left(r_{S}=-\right.$ $3740.15, n=26, P=0.478)$ and competition did not have an effect on the sun's elevation at departure ( $r_{S}$ 
$375=-0.15, n=26, P=0.472))$. Instead of sun's elevation at departure we calculated these correlations

376 also with departure time after sunset, but none was significant.

iii. influence of endogenous factors on sun's elevation at departure

There was no correlation of sun's elevation at departure with stopover duration $\left(r_{S}=-0.037, n\right.$

$380=26, P=0.856)$, departure fuel load $\left(r_{S}=-0.093, n=26, P=0.652\right)$, and deviation of the departure

381 direction from the final migratory goal $\left(r_{C-L}=0.033, n=26, F_{2,23} \approx 0.79, P \approx 0.693\right)$. We tested the

382 effect of the flight vector on sun's elevation by combining departure fuel load, flight direction and

383 their interactions in a linear model. To accommodate the departure direction in the linear model, we

384 included the corresponding sine and cosine values instead of the angular values. This model did not

385 explain a significant proportion of the variability in the departure time of Northern Wheatears $\left(F_{5,20}=\right.$

$\left.3862.47, a d j-R^{2}=0.227, n=26, P=0.068\right)$. We calculated these correlations and model also with

387 departure time after sunset, but none proofed to be significant either.

\section{Departure direction}

Oenanthe wheatears departed in directions between northwest and southeast (Fig. 1).

391 Distribution of departure direction was unimodal (Rayleigh's test: $z=0.69, n=17, P<0.001$ ) with a mean direction of $80^{\circ}(r=0.69, n=17)$. In contrast, leucorhoa wheatears did not show a preferred departure direction (Rayleigh's test: $z=0.08, n=9, P=0.94$; Fig. 2). There was no effect of season on

394 the departure direction for both subspecies separately and combined (for all three correlations $r_{C-L}<$ $0.10, F<1.5, P>0.50)$.

\section{i. influence of weather on departure direction}

Wind direction did not correlate with departure direction of Northern Wheatears; this was

400 neither the case for German Weather Service, NOAA data, nor in respect of the subspecies $\left(r_{C-C}:\right.$ all $P$

$401>0.05)$. Departure direction did not correlate with available tailwind component at the four different

402 pressure levels (for all four correlations $r_{C-L}<0.25, n=26, F_{2,23}<1.4, P>0.05$ ), though all correlation 
coefficients were positive. The lacking effect of tailwind component on departure direction might be explained by low values of tailwind: at $1000 \mathrm{mb}$ pressure level tailwind component was (mean \pm SD) $1.23 \pm 4.48 \mathrm{~m} / \mathrm{s}\left[1^{\text {st }}\right.$ quantile: $-2.8 \mathrm{~m} / \mathrm{s}, 3^{\text {rd }}$ quantile: $\left.4.7 \mathrm{~m} / \mathrm{s}\right]$, at $925 \mathrm{mb} 0.45 \pm 4.35 \mathrm{~m} / \mathrm{s}[-2.1 \mathrm{~m} / \mathrm{s}, 2.9$ $\mathrm{m} / \mathrm{s}]$, at $850 \mathrm{mb} 0.11 \pm 3.64 \mathrm{~m} / \mathrm{s}[-2.0 \mathrm{~m} / \mathrm{s}, 2.3 \mathrm{~m} / \mathrm{s}]$, and at $700 \mathrm{mb} 0.05 \pm 4.31 \mathrm{~m} / \mathrm{s}[-3.0 \mathrm{~m} / \mathrm{s}, 3.5 \mathrm{~m} / \mathrm{s}]$ $(n=26)$, respectively.

\section{ii. effect of departure fuel load on departure direction}

Departure fuel load did not differ significantly between oenanthe (mean \pm SD: $0.14 \pm 0.08, n$ $=17$ ) and leucorhoa wheatears (mean \pm SD: $0.22 \pm 0.23, n=9$; Wilcoxon signed-ranks test: $T=71, P$ $=0.787)$. Departure direction of all Northern Wheatears correlated significantly with departure fuel load $\left(r_{C-L}=0.59, n=26, F_{2,23} \approx 8.4\right.$, bootstrap: $n=2000, P \approx 0.021$; Fig. 7). This means the higher the departure fuel load, the stronger was the northwards component in the departure direction. Such circular-linear correlations were not significant on the subspecies-level (for both correlations: $r_{C-L}<$ $0.37, F<3.48, P>0.23)$. Leucorhoa wheatears having departed towards northwest carried high fat loads enabling flight bouts of more than $700 \mathrm{~km}(800,1312$, and $2521 \mathrm{~km})$. Birds departing in any other direction had in general lower fuel loads and hence, lower flight ranges. Only one of those had a potential flight range of about $1380 \mathrm{~km}$ but flew southwards $\left(162^{\circ}\right)$; mean flight range $\pm \mathrm{SD}$ of the remaining five birds was $331 \pm 251 \mathrm{~km}(n=5$; Fig. 2$)$.

\section{Discussion}

\section{Departure behaviour}

Migrants did not show a higher activity on the ground during departure night than on previous nights (Fig. 4). Birds are either generally resistant to sleep deprivation during migration (Rattenborg et al. 2004), or might recover from the overall lack of sleep by some diurnal naps (Fuchs et al. 2006).

\section{Some Northern Wheatears showed a high activity on the ground even after sunset suggesting feeding}


behaviour, as shown and implied by other studies (Palmgren 1949; Morton 1967; Ramenofsky et al. 2003).

About one half of the birds performed exploratory flights on departure nights and before. It seems unlikely that these flights could had been initiated by disturbance, because flights lasted up to several minutes and some birds returned to the initial site, which seems unlikely in case of disturbance. One might assume that early exploratory flights should indicate early departures from the stopover site and hence indicate a temporal relation between both of them. However, the time of the first exploratory flight until departure did not correlate with sun's elevation at departure (Fig. 6). The reason for this remains unclear. Although some of the exploratory flights shown on Helgoland might be aborted migratory flights of birds being reluctant to continue flying when facing the large sea crossing, we suppose that the exploratory flights are a general behaviour of nocturnal migrants. They might serve (1) to test orientation abilities (Mukhin et al. 2005), (2) to familiarize themselves with the environment for upcoming departure, here e.g. detecting the distance to the nearest coast, (3) to examine the meteorological conditions aloft for potential departure, or (4) might be caused by strong migratory restlessness (“Zugunruhe”; Gwinner 1990). Similar but longer lasting exploratory flights were detected in young Reed Warblers, Acrocephalus scirpaceus. These were interpreted as premigratory flights to develop stellar compass and for gathering information of geographical cues (Mukhin et al. 2005). We suggest that exploratory flights are a common behaviour of nocturnally migrating songbirds to evaluate meteorological conditions aloft, as suggested by Liechti (2006). Schaub et al. (2004) even pointed out that a crucial point for understanding departure decisions of migrants is to discover, how migrants predict wind conditions aloft.

\section{Departure time}

Northern Wheatears did not depart within a fixed time window after sunset but significantly more departed after the Nautical Twilight Period than before (Fig. 3), which are both in line with other radio telemetry studies (Cochran et al. 1967; Åkesson et al. 1996a; Moore \& Aborn 1996; Åkesson et al. 2001; Bolshakov \& Chernetsov 2004; Cochran et al. 2004; Bolshakov et al. 2007) or mist-netting studies (Bolshakov et al. 2003; Bulyuk \& Tsvey 2006). The skylight polarization pattern, used to 
calibrate the compass systems (Cochran et al. 2004; Muheim et al. 2006b, 2007), is available before and during but not after the Nautical Twilight Period. Birds departing after this period might have explored the polarization pattern until its disappearance. Even under overcast situations the skylight polarization pattern is available (Hegedüs et al. 2007), so that the availability of stars or in turn the cloud cover is not likely to influence the schedule of nocturnal departure, as in our and other study species: Summer Tanagers, Piranga rubra, Reed Warblers, and European Robins, Erithacus rubecula (Moore \& Aborn 1996; Åkesson et al. 2001; Bulyuk \& Tsvey 2006; Bolshakov et al. 2007). However, Hylochicla thrushes from North America departed later at night with an increasing cloud cover (Cochran et al. 1967).

In contrast to the high variation in departure times after sunset found in individually radiotagged songbirds (Moore \& Aborn 1996; Åkesson et al. 2001; Bolshakov et al. 2007; this study) and the two hours lasting exodus of nocturnal migrants detected by radar (Liechti et al. 1997, Bruderer \& Liechti 1999), Cochran (1987) found a very restricted time period (range 9-13 min after evening civil twilight) for one migratory Swainson's Thrush, Catharus ustulata, being radio tracked for seven successive nights. In accordance with this result is a consistency in the initiation of flight activity of captive Redstarts, Phoenicurus phoenicurus, in consecutive nights demonstrating that the internal clock might govern the timing of migratory behaviour (Coppack et al. 2008), though contrary results were shown by Palmgren (1949). These studies indicate that individual migrants might have a preferred departure time within the night. Because we could track our study birds only once, we could not assess whether individuals departed at the same time in consecutive nights. An autonomous circadian clock might purport the preferred time window for departure, environmental and migrant's body condition will, however, most likely modulate the exact time of the departure within the genetically predetermined time window (Åkesson et al. 2001; Bulyuk \& Tsvey 2006). The relation between the environment and the endogenous rhythms might be highly complex, which might disguise clear effects of single meteorological conditions on departure time within the night (Bulyuk \& Tsevy 2006). 
In contrast to other studies (Åkesson \& Hedenström 2000, Åkesson et al. 2002, Schaub et al. 2004, Liechti 2006), wind direction did not have an influence on the departure direction of Northern Wheatears. Because experienced tailwind (mean: $1 \mathrm{~m} / \mathrm{s} ; 1^{\text {st }}$ quantile: $-3.0 \mathrm{~m} / \mathrm{s}, 3^{\text {rd }}$ quantile: $4.7 \mathrm{~m} / \mathrm{s}$ ) and general wind speed (seasonal mean $\pm \mathrm{SD}: 6.6 \pm 2.6 \mathrm{~m} / \mathrm{s}, n=34$ ) were much lower than bird's potential airspeed of $13 \mathrm{~m} / \mathrm{s}$ (Bruderer and Boldt 2001), and because only strong winds (headwinds > 5 $\mathrm{m} / \mathrm{s}$ ) were assumed to influence departure direction (Åkesson et al. 2002) and departure decision (Erni et al. 2002; Schaub et al. 2004), both were not influenced as strongly by wind in this study than as in others.

The mean departure direction of oenanthe wheatears $\left(80^{\circ}, r=0.69, n=17\right.$; Fig. 1$)$ in this study differed significantly from the more northwards orientated direction determined by Dierschke \& Delingat (2003) during a release experiment on Helgoland $\left(10^{\circ}, r=0.63, n=17\right.$; Watson's TwoSample Test of Homogeneity: test statistic $=0.256, P<0.05)$. Birds from Dierschke \& Delingat (2003) were kept in captivity with food ad libitum for several days and were released after sunset with a light stick attached to their tail feathers allowing tracking them for about $1 \mathrm{~km}$ by means of binoculars. Owing to the more northbound departure direction, we would expect higher departure fuel loads and with that longer flight ranges in their oenanthe wheatears than in our birds. However, the contrary was the case (mean departure fuel load \pm SD: Dierschke \& Delingat (2003), $0.07 \pm 0.09, n=$ 17; this study, $0.14 \pm 0.08$; Wilcoxon signed-ranks test: $W=81, n_{\text {oenanthe }}=17, P=0.0287$ ). Besides body condition, birds' origin might explain deviant departure directions in the two studies. Only few wheatears of British origin were probably in our study, because mean wind direction was $67^{\circ}$ (Rayleigh's test: $z=0.42, n=863, P<0.0001,24$ measurements per day on ground) and westerly wind prevailed only on two days. In Dierschke \& Delingat's (2003) study, wind came from westerly directions during one third of the study period, so that a higher proportion of British wheatears might have been drifted towards Helgoland than in our study. Thus, more birds could have departed towards northwest in their than in our study to compensate for the drift.

Departure direction of oenanthe and leucorhoa wheatears correlated significantly with their departure fuel load. Migrants with a high departure fuel load headed further northwards than lean 
birds, which generally headed towards the nearest coastline. Similar results were found in orientation

515 experiments of thrushes and larks also during spring migration (Sandberg \& Moore 1996; Sandberg 2003; Deutschlander \& Muheim 2009). There, only birds with high fuel loads showed their seasonally appropriate migratory direction in orientation cages in front of an ecological barrier, whereas lean birds avoided this direction. A similar, though owing to the small sample size not statistically verifiable phenomenon was shown by our leucorhoa wheatears. The three leucorhoa wheatears that departed towards northwest carried sufficient fuel loads for a successful flight of at least $700 \mathrm{~km}$ to cross the North Sea without any wind assistance (mean \pm SD: $1544 \pm 883 \mathrm{~km}, n=3$ ). Also the two oenanthe wheatears departing towards northwest or north had such high fuel loads (Fig. 7). Other leucorhoa wheatears had generally lower fuel loads and departed in any other direction. This tendency is supported by the release experiment from Dierschke \& Delingat (2003). Their leucorhoa wheatears had relatively high mean departure fuel loads corresponding to mean \pm SD potential flight ranges of $967 \pm 641 \mathrm{~km}(n=8)$. If considering only those birds with a flight range exceeding $700 \mathrm{~km}$, distribution of departure direction was unimodal towards northwest $\left(298^{\circ}\right.$; Rayleigh test: $z=0.70, n=$ $6, P=0.0474)$. Thus, there are hints that leucorhoa wheatears only cross the North Sea towards northwest, if they possess high departure fuel loads, whereas lean migrants are more reluctant to proceed their migration across ecological barriers (Alerstam 1978, 2001; Sandberg \& Moore 1996; Sandberg 2003; Deutschlander \& Muheim 2009). Deviations from the seasonal appropriated migratory direction were known from field observations (Koch 1934; von Haartman 1945; von Haartman et al. 1946; Rabøl 1969; Alerstam 1978; Richardson 1982), ring recovery analyses (Åkesson et al. 1996b),

534 orientation cage experiments (Sandberg \& Moore 1996; Sandberg et al. 2002; Sandberg 2003;

535 Deutschlander \& Muheim 2009), radar (Richardson 1982; Liechti \& Bruderer 1995; KomendaZehnder et al. 2002), and infra-red studies (Zehnder et al. 2002). Migrants might have left the stopover sites because of strong competition (Rappole \& Warner 1976; Moore \& Yong 1991), high predation danger (Lindstöm 1990; Moore 1994; Fransson \& Weber 1997), and/or low quality stopover sites

539 (Ktitorov et al. 2008). Orientation away from any inhospitable habitat seems to be an adaptive 540 behaviour for lean birds (Alerstam 1978; Lindström \& Alerstam 1986; Sandberg \& Moore 1996;

541 Sandberg et al. 2002; Sandberg 2003; Deutschlander \& Muheim 2009) and might reduce the apparent 
542 high mortality rate on migration (Sillett \& Holmes 2002). Although unfavourable weather (Richardson

543 1990) and errors in orientation (Komenda-Zehnder et al. 2002; Zehnder et al. 2002) will lead to

544 reverse migration as well, most reverse migration is an individual-based and intended reaction up on

545 the actual stopover situation.

546 Coming from their Sahelian wintering areas leucorhoa wheatears have to eventually switch

547 their migratory direction from north to northwest or even west to reach their breeding areas on Iceland,

548 Greenland or Eastern Canada during spring migration. Such a switch in the migratory direction is

549 likely to be genetically determined (Gwinner \& Wiltschko, 1978; Helbig et al. 1989), but in leucorhoa

550 wheatears such a change in the migratory direction is only of use, if birds have stored sufficient fuel

551 load and selected favourable meteorological conditions to successfully cross the Atlantic. Migrants

552 are, therefore, supposed to refuel intensively before crossing this marine obstacle as many songbird

553 migrants do before crossing the Sahara (Odum 1963). We hypothesize that the trigger to actually

554 perform the genetically determined migratory shift towards northwest might be the interplay of

555 migrant's high fuel load and favourable meteorological conditions for the Atlantic crossing.

556

557

558

559

560

561

562

563

564

565

566

567

Acknowledgement

We are extremely grateful to Franz Bairlein who helped and supported this project in various ways. Volker Dierschke kindly provided some additional data about the release experiments on

Helgoland. Continuous field work was only possible because of important support from Ommo Hüppop, Freimut Schramm, Felix Jachmann, and several volunteers of the Institute of Avian Research "Vogelwarte Helgoland". Meteorological data were kindly supplied by Deutscher Wetterdienst and the NOAA-CIRES Climate Diagnostics Center, Boulder, Colorado, from their Web site at http://www.cdc.noaa.gov/. Northern Wheatears were caught, ringed, and radio-tagged under a licence from the Ministry for Agriculture, the Environment and Rural Areas, Schleswig-Holstein, Germany. We also wish to thank Ulric Lund very much for his advice about circular statistics. We are very 
568 grateful for valuable comments on this manuscript to Franz Bairlein, Lukas Jenni, and two anonymous 569 referees. 


\section{References}

571 Åkesson S, Alerstam T, Hedenström A (1996a) Flight initiation of nocturnal passerine migrants in relation to celestial orientation conditions at twilight. J Avian Biol 27:95-102

Åkesson S, Karlsson L, Walinder G, Alerstam T (1996b) Bimodal orientation and the occurrence of temporary reverse bird migration during autumn in south Scandinavia. Behav Ecol Sociobiol 38:293-302

Åkesson S, Hedenström A (2000) Wind selectivity of migratory flight departures in birds. Behav Ecol Sociobiol 47:140-144

Åkesson S, Walinder G, Karlsson L, Ehnbom S (2001) Reed warbler orientation: initiation of nocturnal migratory flights in relation to visibility of celestial cues at dusk. Anim Behav 61:181189

Åkesson S, Walinder G, Karlsson L, Ehnbom S (2002) Nocturnal migratory flight initiation in reed warblers Acrocephalus scirpaceus: effect of wind on orientation and timing of migration. J Avian Biol 33:349-357

Alerstam T (1978) Reoriented bird migration in coastal areas: dispersal to suitable testing grounds? Oikos 30:247-256

Alerstam T, Lindström Å (1990) Optimal bird migration: the relative importance of time, energy, and safety. In: Gwinner E (ed) Bird Migration: Physiology and Ecophysiology, Springer Verlag, Berlin, pp 331-351

Alerstam T (2001) Detours in Bird Migration. J Theor Biol 209:319-331

Bairlein F (1994) Manual of Field Methods. European-African Songbird Migration Network.

$591 \quad$ Wilhelmshaven

592 Batschelet E (1981) Circular statistics in biology. Academic Press, London

593 Bolshakov CV, Bulyuk V, Chernetsov N (2003) Spring nocturnal migration of Reed Warblers

594 Acrocephalus scirpaceus: departure, landing and body condition. Ibis 145:106-112

595 Bolshakov CV, Chernetsov N (2004) Initiation of nocturnal flight in two species of long-distance

596 migrants (Ficedula hypoleuca and Acrocephalus schoenobaenus) in spring: a telemetry study.

$597 \quad$ Avian Ecol Behav 12:63-76 
Bolshakov CV, Chernetsov N, Mukhin A, Bulyuk V, Kosarev VV, Ktitorov P, Leoke D, Tsvey A (2007) Time of nocturnal departures in European robins, Erithacus rubecula, in relation to celestial cues, season, stopover duration and fat score. Anim Behav 74:855-865

Bruderer B, Liechti F (1995) Variation in density and height distribution of nocturnal migration in the south of Israel. Israel J Zool 41:477-487

Bruderer B, Liechti F (1999) Bird migration across the Mediterranean. In: Adam N, Slotow R (eds) Proceedings of the 22nd International Ornithological Congress. BirdLife South Africa, Durban, pp 1983-1999

Bruderer B, Boldt A (2001) Flight characteristics of birds: I. radar measurements of speeds. Ibis

Bulyuk VN, Tsvey A (2006) Timing of nocturnal autumn migratory departures in juvenile European Robins (Erithacus rubecula) and endogenous and external factors. J Ornithol 147:298-309

610 Caccamise DF, Hedin RS (1985) An aerodynamic basis for selecting transmitter loads in birds. Wilson Bulletin 97:306-318

\section{2}

Cochran WW, Montgomery GG, Graber RR (1967) Migratory flights of Hylocichla thrushes in spring: a radiotelemetry study. Living Bird 6:213-225

Cochran WW (1980) Wildlife telemetry. In: Schemnitz S (ed) Wildlife management techniques manual, The Wildlife Society, Washington, pp 507-520

616 Cochran WW (1987) Orientation and other migratory behaviours of a Swainson's Thrush followed for 1500 km. Anim Behav 35:927-929

Cochran WW, Mouritsen H, Wikelski M (2004) Migrating Songbirds Recalibrate Their Magnetic Compass Daily from Twilight Cues. Science 304:405-408

Cooke SJ, Hinch SG, Wikelski M, Andrews RD, Kuchel LK, Wolcott TG, Butler PJ (2004) Biotelemetry: a mechanistic approach to ecology. TREE 19:334-343

622 Coppack T, Becker SF, Becker PJJ (2008) Circadian flight schedules in night-migrating birds caught 623 on migration. Biol Letters 4:619-622

624 Crawley MJ (2005) Statistical Computing. An Introduction to Data Analysis using S-Plus. Wiley. New 625 York 
Delingat J, Dierschke V, Schmaljohann H, Mendel B, Bairlein F (2006) Daily stopovers as optimal migration strategy in a long-distance migrating passerine: the Northern Wheatear. Ardea 94:593605

Delingat J, Bairlein F, Hedenström A (2008) Obligatory barrier crossing and adaptive fuel management in migratory birds: the case of the Atlantic crossing in Northern Wheatears (Oenanthe oenanthe). Behav Ecol Sociobiol 62:1069-1078

Delingat J, Dierschke V, Schmaljohann H, Bairlein F (2009) Diurnal patterns of body mass change during stopover in a migrating songbird. J Avian Biol 40:625-634

Deutschlander ME, Muheim R (2009) Fuel reserves affect migratory orientation of thrushes and sparrows both before and after crossing an ecological barrier near their breeding grounds. J Avian Biol 40:1-5

Dierschke V, Delingat J (2003) Stopover of Northern Wheatears Oenanthe oenanthe at Helgoland: where do the migratory routes of Scandinavian and Nearctic birds join and split? Ornis Svecica

Dierschke V, Mendel B, Schmaljohann H (2005) Differential timing of spring migration in Northern

Erni B, Liechti F, Underhill LG, Bruderer B (2002) Wind and rain govern the intensity of nocturnal bird migration in central Europe - a log-linear regression analysis. Ardea 90:155-166

Fransson T, Weber TP (1997) Migratory fueling in blackcaps (Sylvia atricapilla) under perceived risk of predation. Behav Ecol Sociobiol 41:75-80

Fuchs T, Haney A, Jechura TJ, Moore FR, Bingman V (2006) Daytime naps in night-migrating birds: behavioural adaptation to seasonal sleep deprivation in the Swainson's thrush, Catharus ustulatus. Anim Behav 72:951-958

Gauthreaux SA, Belser CG (1999) Bird migration in the region of the Gulf of Mexico. In: Adam N, 650 Slotow R (eds) Proceedings of the 22nd International Ornithological Congress. BirdLife South $651 \quad$ Africa, Durban, pp 1931-1947

652 Goyman W, Spina F, Ferri A, Fusani L (2010) Body fat influences departure from stopper sites in 653 migratory birds: evidence from whole-island telemetry. Biol letters. Published online. 
654 Gwinner E, Wiltschko W (1978) Endogenously controlled changes in migratory direction of the 655 garden warbler, Sylvia borin. J Comp Physiol 125:267-273

656 Gwinner E (1990) Circannual rhythms in bird migration: Control of temporal patterns and interactions 657 with photoperiod. In: Gwinner E (ed) Bird Migration: Physiology and Ecophysiology, Springer $658 \quad$ Verlag, Berlin, pp 257-268

659 Haartman L von (1945) Umschlagende Zugrichtung beim Buchfinken, Fingilla c. coelebs L., im $660 \quad$ Herbst. Ornis Fennica 22:10-16

661 Haartman L von, Bergman G, Koskimies J (1946) Beobachtungen über umschlagende Zugrichtung der 662 Bachstelze, Motacilla alba L., im Herbst. Ornis Fennica 23:50-62

663 Hedenström A, Alerstam T (1997) Optimum Fuel Loads in Migratory Birds: Distinguishing Between 664 Time and Energy Minimization. J Theor Biol 189:227-234

665 Hedenström A (2008) Adaptations to migration in birds: behavioural strategies, morphology and 666 scaling effects. Phil T Royal Soc Lond B 363:287-299

667 Hegedüs R, Åkesson S, Horváth G (2007) Polarization patterns of thick clouds: overcast skies have 668 distribution of the angle of polarization similar to that of clear skies. J Optic Soc Am A 24:23476692356

670 Helbig AJ, Berthold P, Wiltschko W (1989) Migratory orientation of blackcaps (Sylvia atricapilla): 671 population-specific shifts of direction during the autumn migration. Ethol 82:307-315

672 Houston AI (1998) Models of optimal avian migration: state, time and predation. J Avian Biol $673 \quad 29: 395-404$

674 Irvine RJ, Leckie F, Redpath SM (2007) Cost of Carrying Radio Transmitters: a Test with Racing 675 Pigeons Columba Livia. Wildlife Biol 13:238-243

676 Jammalamadaka SR, SenGupta A (2001) Topics in Circular Statistics. World Scientific Publishing, $677 \quad$ Singapore

678 Jenni L, Schaub M (2003) Behavioural and Physiological Reactions to Environmental Variation in 679 Bird Migration: a review. In: Berthold P, Gwinner E, Sonnenschein E (eds). Avian Migration, 680 Springer Verlag, Berlin, pp 155-171 
Kaiser A (1993) A new multi-category classification of subcutaneous fat deposits of songbirds. J Field

682

683

684

685

686

687

688

689

690

691

692

693

694

695

696

697

698

699

700

701

702

703

704

705

706

707

Ornithol 64:246-255

Ktitorov P, Bairlein F, Dubinin M (2008) The importance of landscape context for songbirds on migration: body mass gain is related to habitat cover. Landscape Ecol 23:169-179

Koch JC (1934) Vogelzug unter Einfluss von Leitlinie und Windrichtung. Vogelzug 5:45-52

Komenda-Zehnder S, Liechti F, Bruderer B (2002) Is reverse migration a common feature of nocturnal bird migration? - an analysis of radar data from Israel. Ardea 90:325-334

Lank DB, Ydenberg RC (2003) Death and danger at migratory stopovers: problems with "predation risk". J Avian Biol 34:225-228

Liechti F, Bruderer B (1995) Directions, speed, and composition of nocturnal bird migration in the south of Israel. Israel J Zool 41:510-515

Liechti F, Steuri T, López-Jurado C, Ribas PLD, Reis MA, Bruderer B (1997) Nocturnal spring migration on Mallorca - schedules of departure and passage. Ardeola 44:207-213

Liechti F, Bruderer B (1998) The relevance of wind for optimal migration theory. J Avian Biol 29:561-568

Liechti F (2006) Birds: blowin' by the wind? J Ornithol 147:202-211

Lindström Å, Alerstam T (1986) The adaptive significance of reoriented migration of chaffinch Fringilla coelebs and bramblings $F$. montifringilla during autumn in southern Sweden. Behav Ecol Sociobiol 19:417-424

Lindström $\AA$ (1990) The role of predation risk in stopover habitat selection in migrating bramblings, Fringilla montifringilla. Behav Ecol 1:102-106

Moore FR (1987) Sunset and the orientation behaviour of migrating birds. Biol Rev 62:65-86

Moore FR, Yong W (1991) Evidence of food-based competition among passerine migrants during stopover. Behav Ecol Sociobiol 28:85-90

Moore FR (1994) Resumption of feeding under risk of predation. Anim Behav 48:975-977

Moore FR, Aborn DA (1996) Time of departure by Summer Tanagers (Piranga rubra) from a stopover site following spring trans-gulf migration. Auk 113:949-952 
Morton ML (1967) Diurnal feeding patterns in white-crowned sparrows Zonotrichia leucophrys gambelii. Condor 69:491-512

Mouritsen H, Feenders G, Liedvogel M, Kropp W (2004) Migratory birds use head scans to detect the direction of the earth's magnetic field. Cur Biol 14:1946-1949

Muheim R, Moore FR, Phillips JB (2006a) Calibration of magnetic and celestial compass cues in migratory birds - a review of cue-conflict experiments. J Exp Biol 209:2-17

Muheim R, Phillips JB, Åkesson S (2006b) Polarized light cues underlie compass calibration in migratory songbirds. Science 313:837-839

Muheim R, Åkesson S, Moore FR (2007) Magnetic compass of migratory Savannah sparrows is calibrated by skylight polarization at sunrise and sunset. J Ornithol 148 (Suppl 2):485-494

Mukhin A, Kosarev V, Ktitorov P (2005) Nocturnal life of young songbirds well before migration. Proc R Soc Lond B 272:1535-1539

Naef-Daenzer B (1993) A new transmitter for small animals and enhanced methods of home-range analysis. J Wildlife Manag 57:680-689

Naef-Daenzer B, Widmer F, Nuber M (2001) A test for effects of radio-tagging on survival and movements of small birds. Avian Science 1:15-23

Naef-Daenzer B, Früh D, Stalder M, Wetli P, Weise E (2005) Miniaturization (0.2 g) and evaluation of attachment techniques of telemetry transmitters. J Exp Biol 208:4063-4068

Naef-Daenzer B (2007) An allometric function to fit leg-loop harnesses to terrestrial birds. J Avian Biol 38:404-407

Odum EP (1963) Lipid levels in birds preparing to cross the Sahara. Ibis 105:109-111 R Foundation for Statistical Computing. 〈http://www.R-project.org>. 

Behaviour: New Insights from Captive Studies. In: Berthold P, Gwinner E, Sonnenschein E (eds). Avian Migration, Springer Verlag, Berlin, pp 97-110

Rappole JH, Warner DW (1976) Relationships between behaviour, physiology and weather in avian transients at a migration site. Oecologia 26:193-212

Rappole JH, Tipton AR (1990) New harness design for attachment of radio transmitters to small passerines. J Field Ornithol 62:335-337

Rattenborg NC, Mandt BH, Obermeyer WH, Winsauer PJ, Huber R, Wikelski M, Benca RM (2004) Migratory Sleeplessness in the White-Crowned Sparrow (Zonotrichia leucophrus gambelii). plos Biology 7:924-936

Richardson WJ (1982) Northeastward reverse migration of birds over Nova Scotia, Canada, in Autumn. Behav Ecol Sociobiol 10:193-206

Richardson WJ (1990) Timing of bird migration in relation to weather: updated review. - In:Gwinner E (ed) Bird migration, Springer Verlag, Berlin, pp 78-101

Rozenberg GV (1966) Twilight. A Study in Atmospheric Optics. Plenum, New York

Sandberg R (1994) Interaction of body condition and magnetic orientation in autumn migrating

Sandberg R, Moore FR (1996) Migratory orientation of red-eyed vireos, Vireo olivaceus, in relation to energetic condition and ecological context. Behav Ecol Sociobiol 39:1-10

Sandberg R, Moore FR, Bäckman J, Löhmus M (2002) Orientation of nocturnally migrating Swainson's thrush at dawn and dusk: Importance of energetic condition and geomagnetic cues. Auk 119:201-209

Sandberg R (2003) Stored fat and the Migratory Orientation of Birds. In: Berthold P, Gwinner E, Sonnenschein E (eds). Avian Migration, Springer Verlag, Berlin, pp 515-525

Schaub M, Liechti F, Jenni L (2004) Departure of migrating European robins, Erithacus rubecula, from a stopover site in relation to wind and rain. Anim Behav 67:229-237 migration stopover site. Behav Ecol 19:657-666 
762 Schmaljohann H, Dierschke V (2005) Optimal bird migration and predation risk: a field experiment 763 with Northern Wheatears Oenanthe oenanthe. J Anim Ecol 74:131-138

764 Schmaljohann H, Liechti F, Bruderer B (2007) Songbird migration across the Sahara - the non-stop 765 hypothesis rejected! Proc R Soc Lond B 274:735-739

766 Schwilch R, Piersma T, Holmgren NMA, Jenni L (2002) Do migratory birds need a nap after a long 767

Sillett TS, Holmes RT (2002) Variation in survivorship of a migratory songbird throughout its annual cycle. J Anim Ecol 71:296-308

770 Svensson L (1992) Identification guide to European passerines. Stockholm

771 Tsvey A, Bulyuk VN, Kosarev V (2007) Influence of body condition and weather on departures of first-year European robins, Erithacus rubecula, form an autumn migratory stopover site. Behav Ecol Sociobiol 61:1665-1674

774 Wikelski M, Tarlow EM, Raim A, Diehl RH, Larkin RP, Visser GH (2003) Costs of migration in freeflying songbirds. Nature 423:704

776 Zehnder S, Åkesson S, Liechti F, Bruderer B (2002) Observation of free-flying nocturnal migrants at 777 Falsterbo: occurrence of reverse flight directions in autumn. Avian Science 2:103-113 
Figure 1. Nocturnal activity on the ground two and one days before departure and departure night.

779 Given are means and standard error of percentage, for further information see Methods. "dep day" 780 stands for "departure day" (solid triangle), “dep day - 1" for "one day before departure day" (solid 781 circle) and "dep day - 2" for "two days before departure day" (solid square), respectively. Values per 782 specific day sum up to 1.

784 Figure 2. Nocturnal activity on the ground on the day of departure of oenanthe (solid circles) and 785 leucorhoa (open triangles) wheatears. Given are means and standard error of percentage, for further 786 information see Methods. Values per subspecies sum up to 1.

Figure 3. Departure directions of 17 Northern Wheatears of the oenanthe subspecies. Their mean departure direction was $80^{\circ}(r=0.69, n=17$; Rayleigh's test: $z=0.69, n=17, P<0.001)$ and is 790 indicated by the arrow.

Figure 4. Departure directions of nine Northern Wheatears of the leucorhoa subspecies, which did not show a preferred departure direction (Rayleigh's test: $z=0.08, n=9, P=0.94$ ). Birds with a departure fuel load of $>0.19$ (solid circles) had sufficient fuel load to perform a $800 \mathrm{~km}$ long non-stop flight and could reach Scotland without any additional refuelling.

Figure 5. Time of departure of radio-tagged Northern Wheatears in relation to elevation of the sun on Helgoland in spring. Solid circles refer to oenanthe and open triangles to leucorhoa wheatears, respectively. At Civil Twilight (CT) sun is defined to be $6^{\circ}$, at Nautical Twilight Period (NT) $12^{\circ}$, and at Astronomical Twilight (AT) $18^{\circ}$ below the horizon, respectively. Duration from sunset to certain twilight periods changes in course of the season, i.e., at a certain time after sunset sun's position varies with time of season.

804 Figure 6. Sun's elevation against time of first exploratory flight until dearture. There is no apparent 805 relationship between both variables (Spearman rank correlation: $r_{S}=0.36, n=10, P=0.313$ ). 
807 Figure 7. Departure direction against departure fuel load. For clarity reasons y-axis does not start with $8080^{\circ}$ but $180^{\circ}$, otherwise trend line would be truncated and its meaning not straightforward. Solid circles 809 refer to oenanthe and open triangles to leucorhoa wheatears, respectively. The trend line indicates the 810 direction of the circular-linear correlation (circular-linear correlation: $r=0.59, n=26, F_{2,23} \approx 8.4$,

811 bootstrap: $n=2000, P \approx 0.021$; for statistical details see method section). The directions between north

812 and northwest are highlighted in light grey. All birds departing in any of these directions had a

813 departure fuel load of $\geq 0.19$ enabling flights of $800 \mathrm{~km}$ without any wind assistance.

814 
815

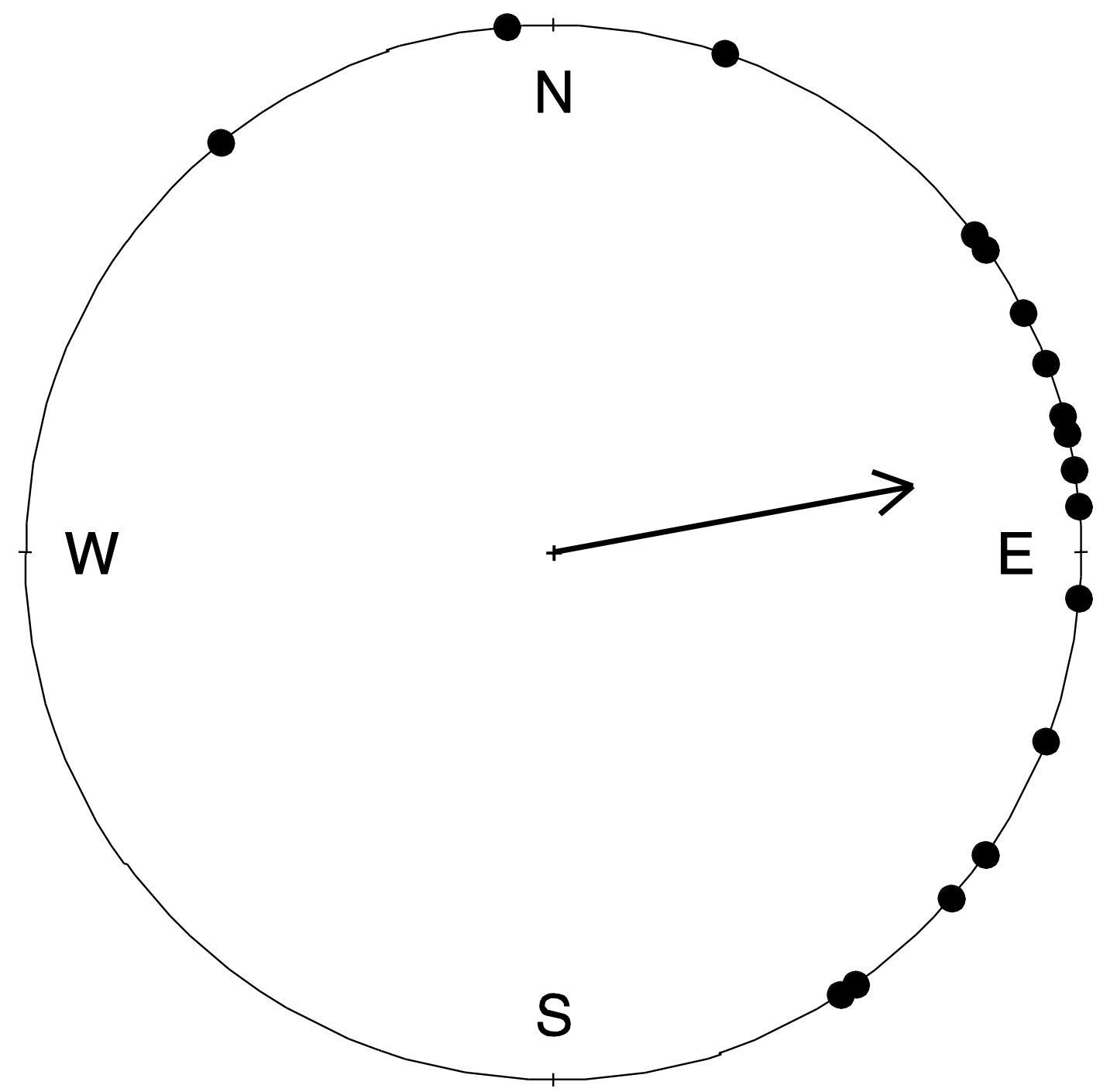

816 


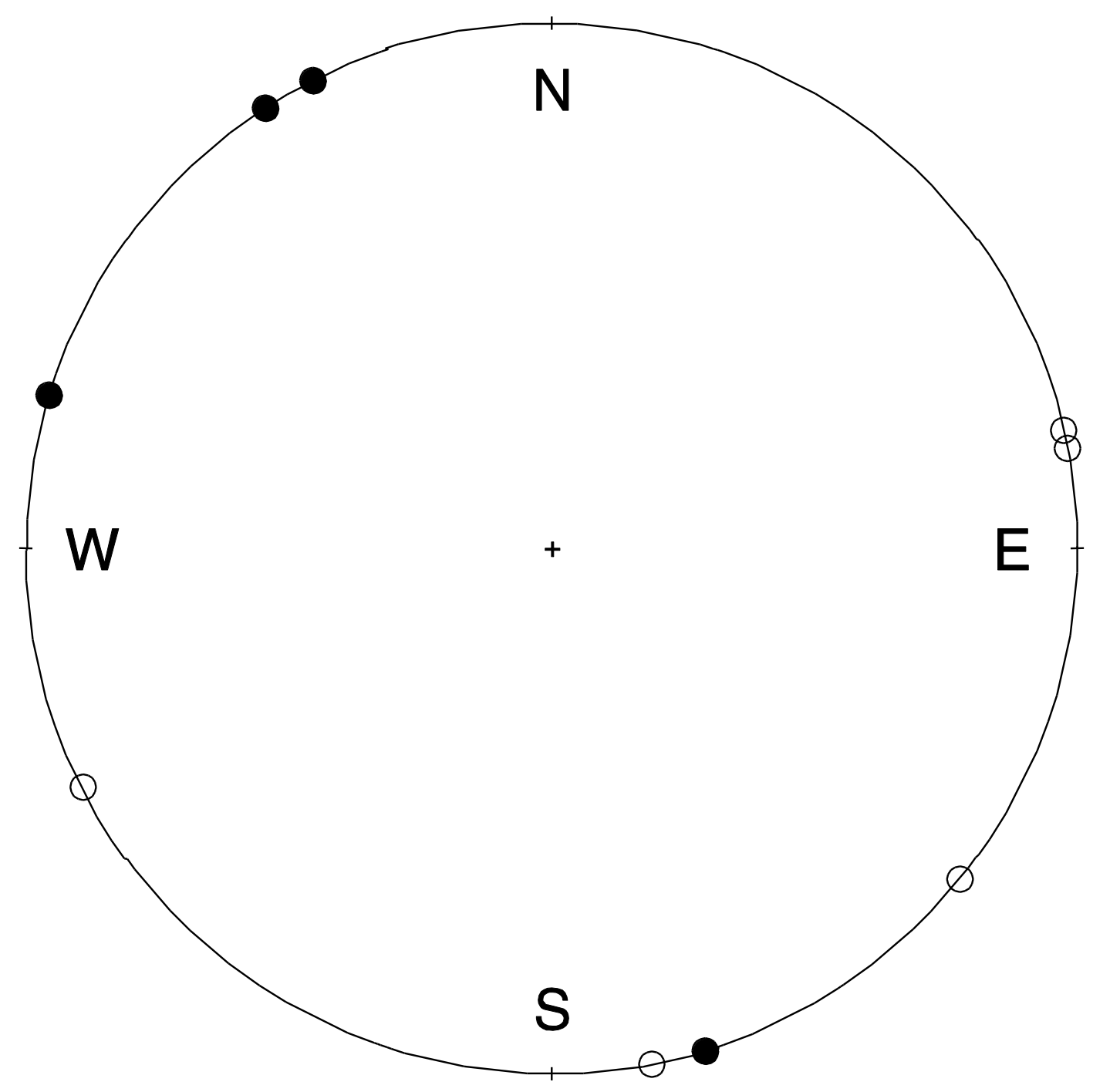

817 


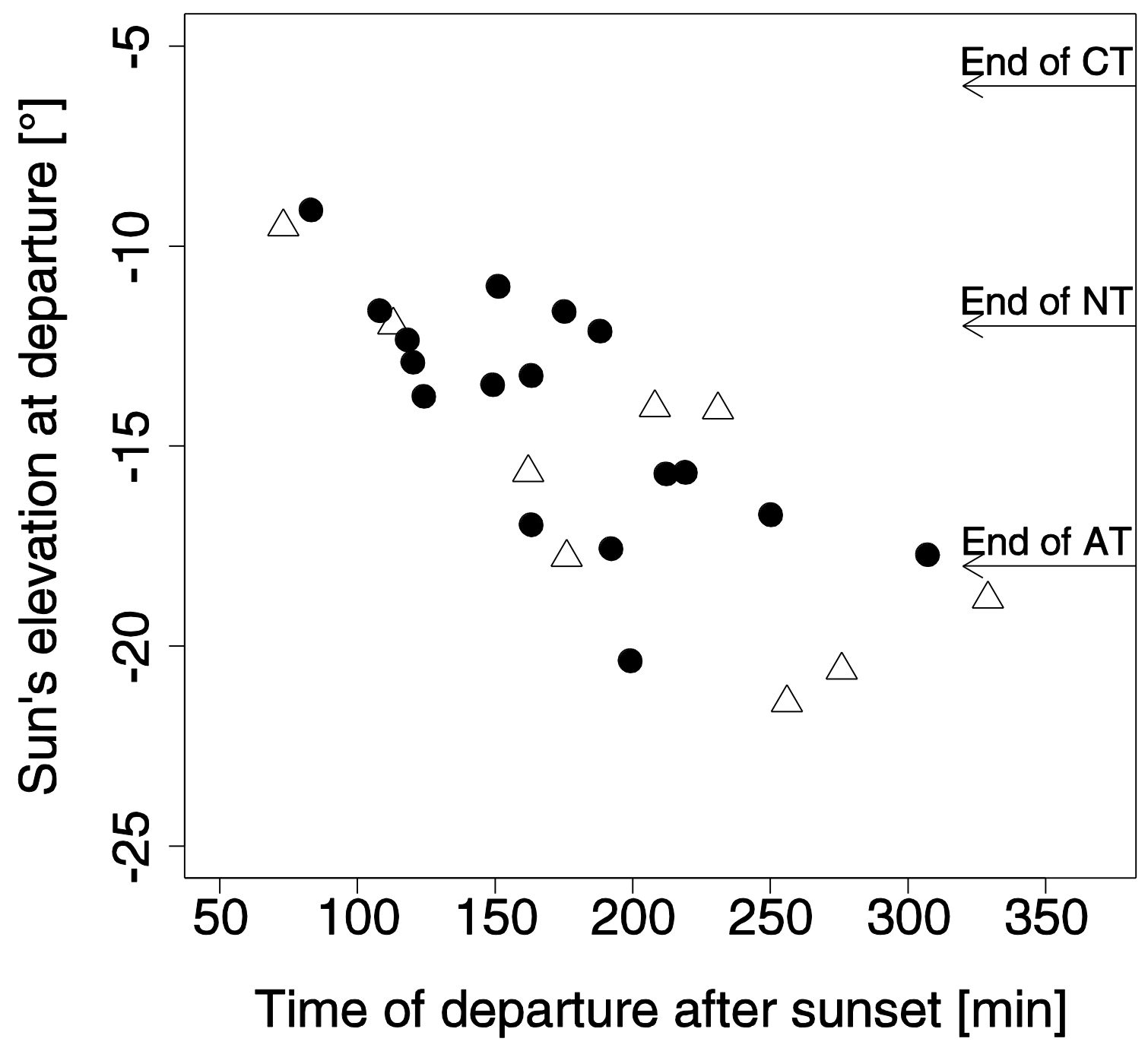

818 


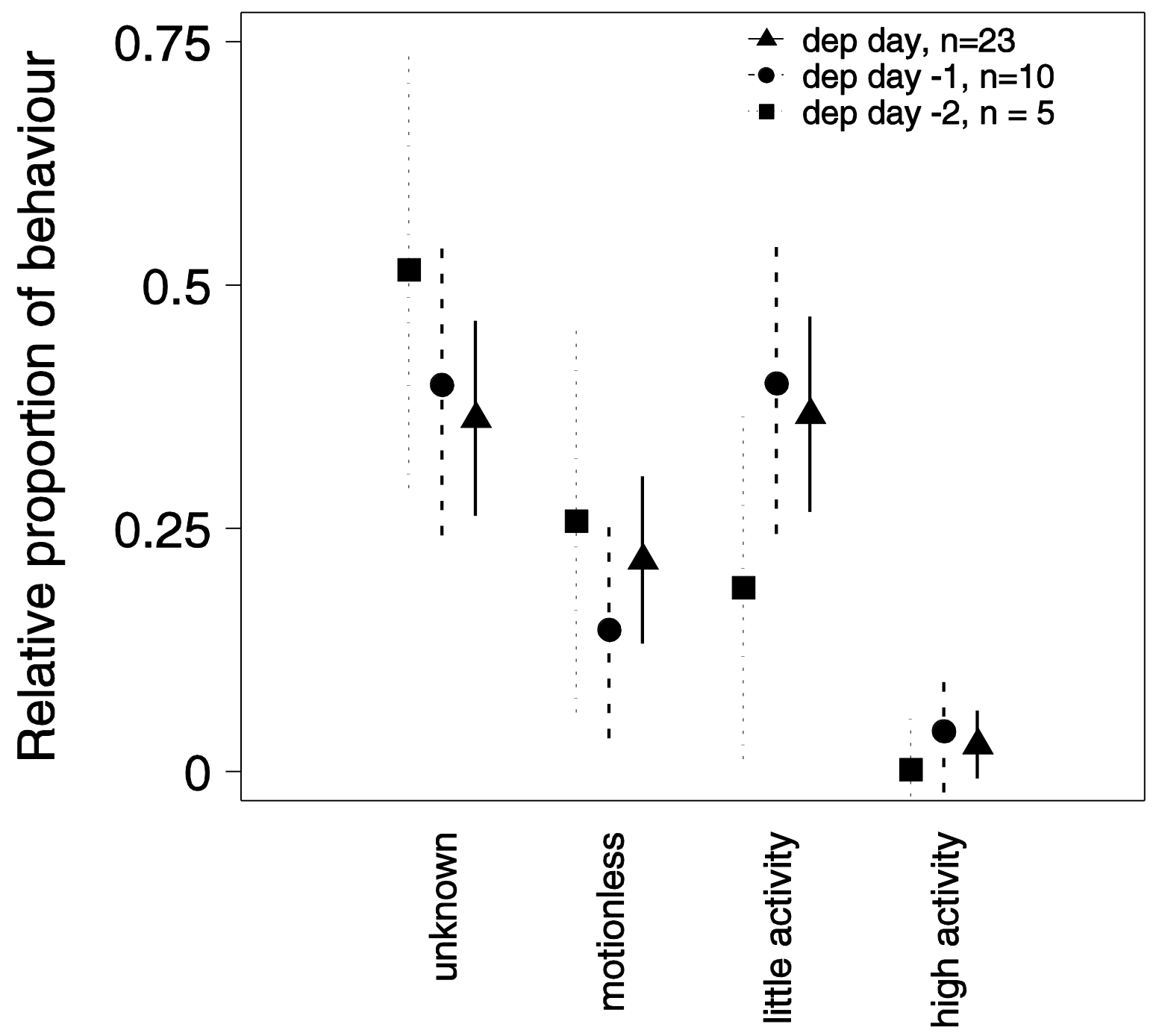

819 


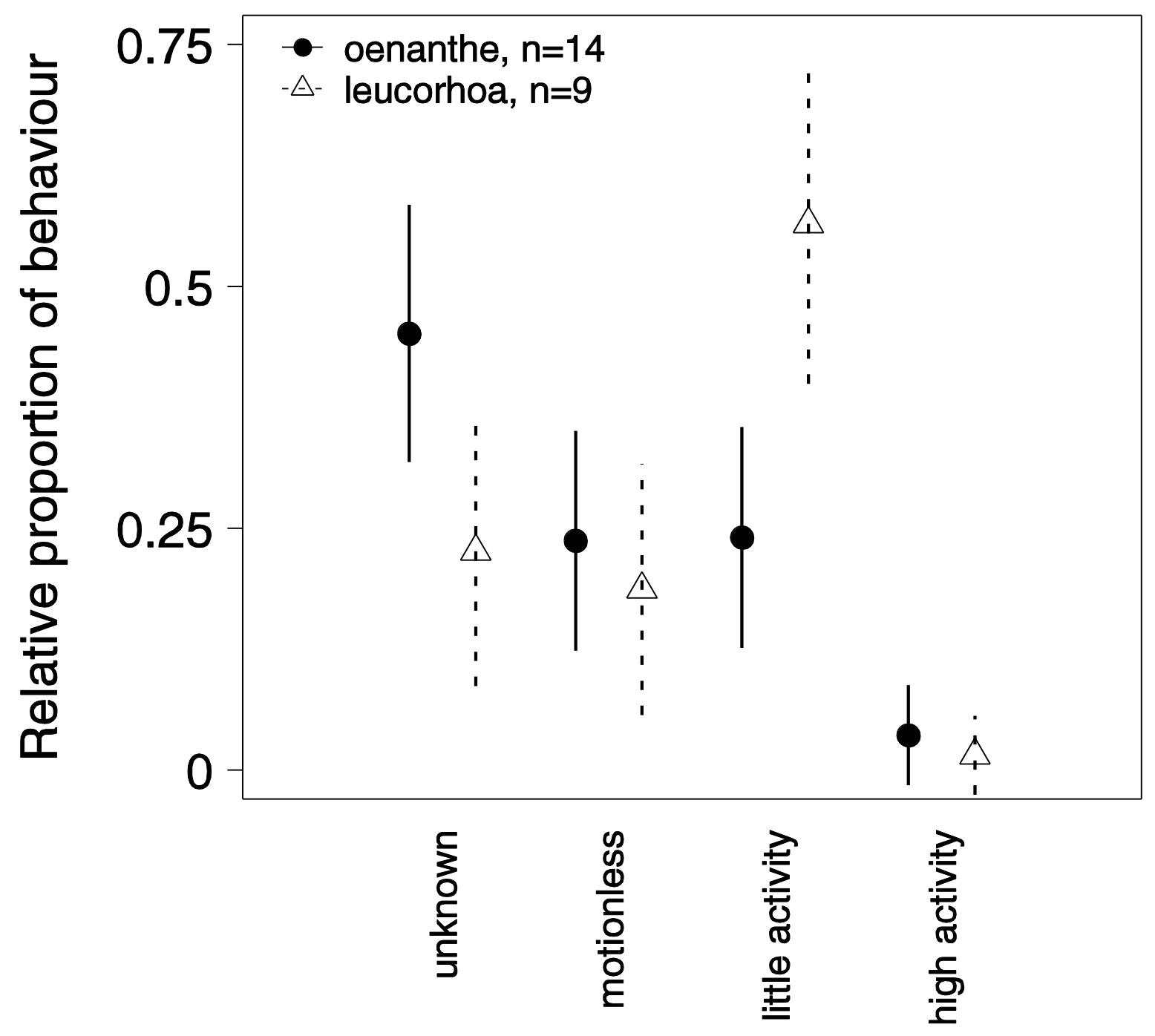

820 


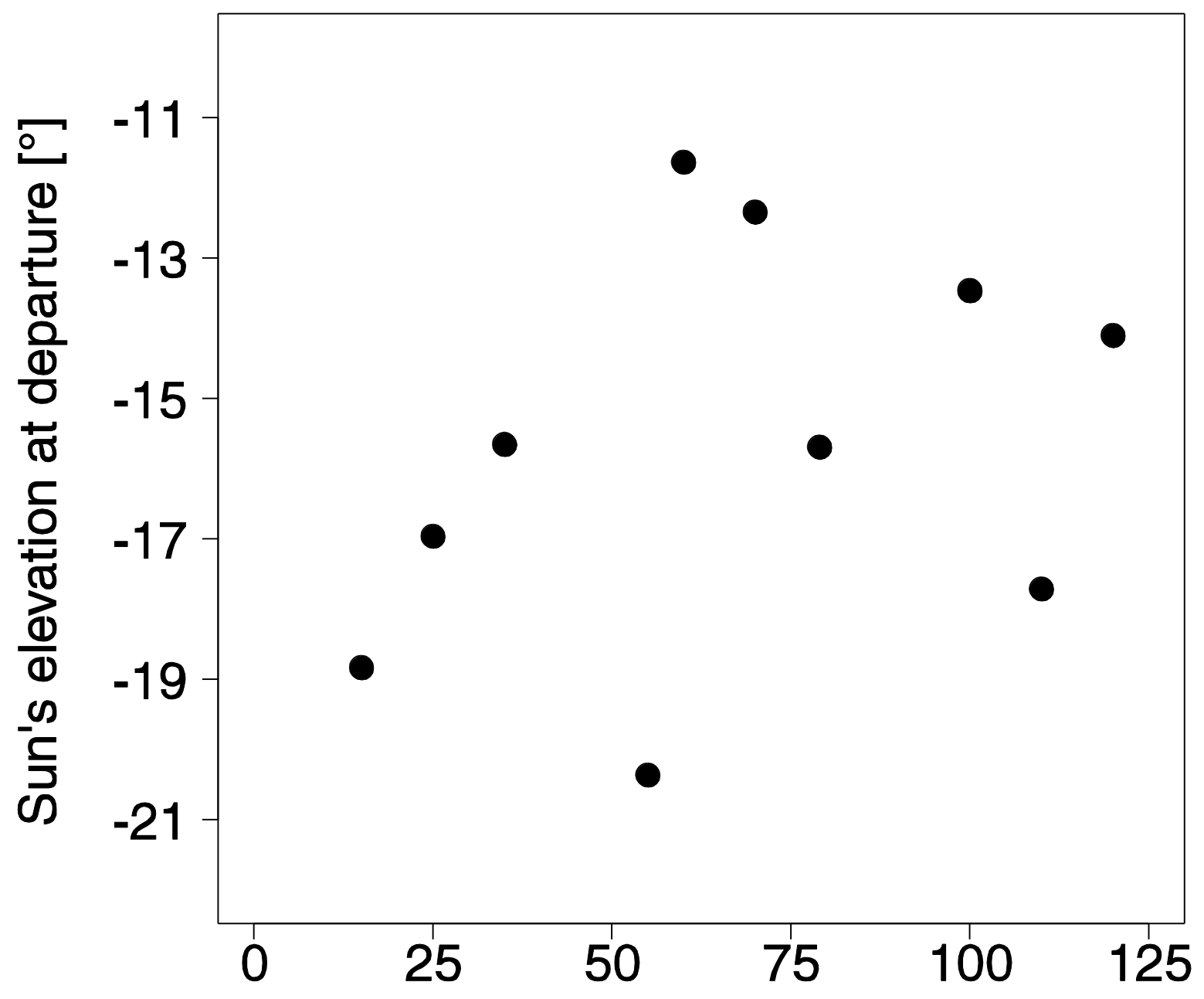

Time of first exploratory flight until departure [m 


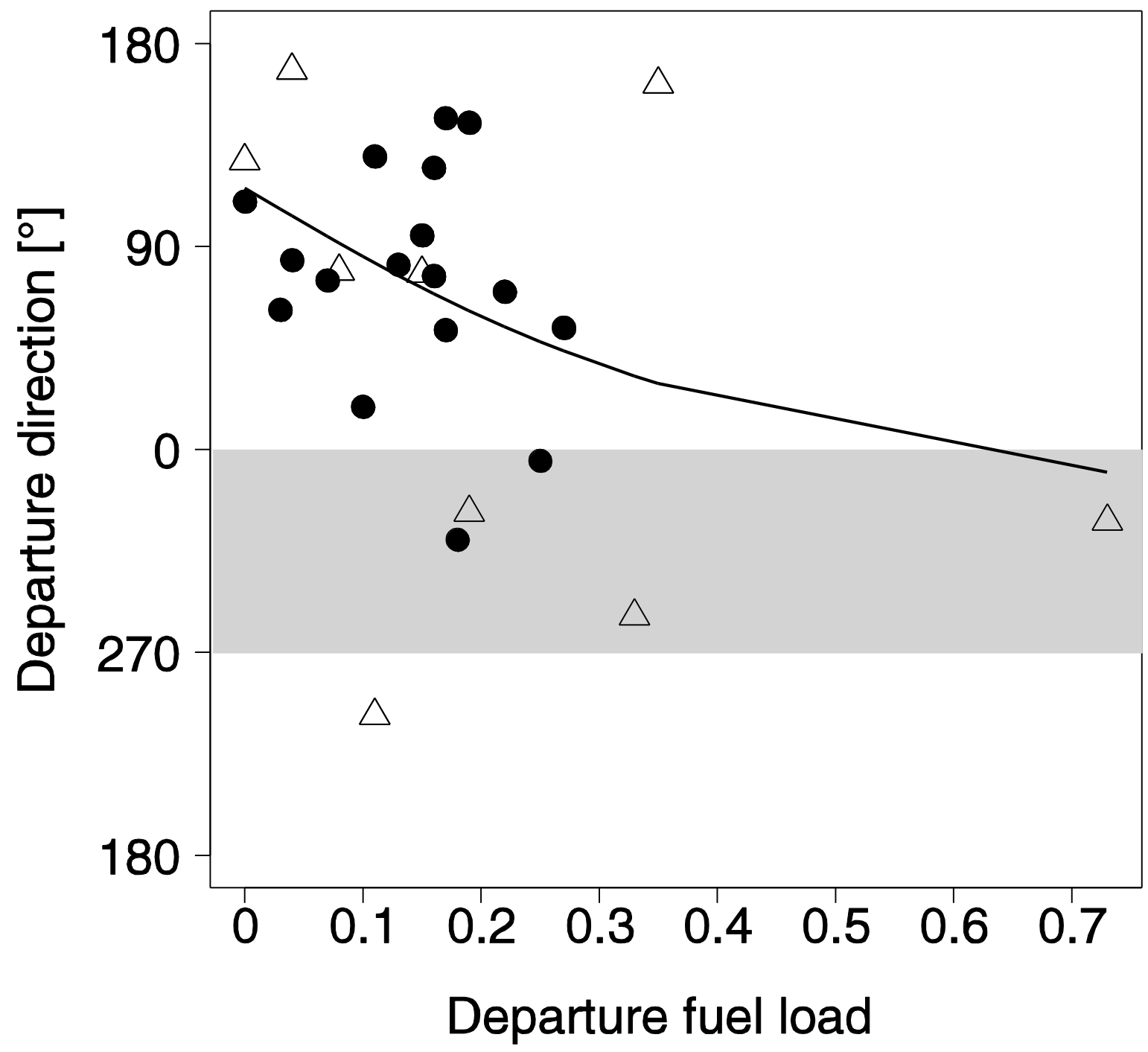

